\title{
Narrativa imersiva em games sonoros: escuta e paisagem sonora em A Blind Legend'
}

IMMERSIVE NARRATIVE IN AUDIO GAMES: LISTENING AND SOUND LANDSCAPE IN A BLIND LEGEND

L Debora Cristina Lopez ${ }^{1}$

ORCID: https://orcid.org/0000-0002-1030-1996

(Universidade Federal de Ouro Preto, Programa de Pós-Graduação em Comunicação, Mariana, Brasil)

João Alves ${ }^{2}$

ORCID: https://orcid.org/0000-0001-6814-2951

(Universidade Federal de Ouro Preto, Programa de Pós-Graduação em Comunicação, Mariana, Brasil)

Recebido em 27/11/2018. Aprovado em 13/08/2019.

\section{Resumo}

Este artigo pretende refletir sobre os recursos usados para a construção de uma narrativa sonora imersiva no jogo "A Blind Legend", desenvolvido pela empresa francesa DOWiNO. Foi realizada uma análise descritiva (TRIVIÑOS, 2008) amparada por operadores analíticos pré-definidos que pretendem amparar a busca pelo desvendamento das estratégias acústicas adotadas e identificar seus potenciais imersivos. Os resultados apontam que A Blind Legend é um jogo sonoro imersivo, que utiliza de estratégias narrativas e técnicas para criar uma ambiência sonora, potencializando novas formas de conteúdo.

Palavras-Chave: Narrativas sonoras. Paisagem sonora. Narrativa imersiva. Jogos digitais.

\section{Abstract}

This article intends to reflect on the resources used to build an immersive sound narrative in the game "A Blind Legend" developed by the French company DOWiNO. A descriptive analysis (TRIVIÑOS, 2008) was carried out supported by pre-defined analytical operators that intend to support the search for the unveiling of the adopted acoustic strategies and to identify their immersive potential. The results point out that A Blind Legend is an immersive sound game that uses narrative and technical strategies to create a sound ambience, enhancing new forms of content.

Keywords: Audio narratives. Sound landscape. Immersive narrative. Digital games.

${ }^{1}$ Este artigo foi construído a partir da versão inicial, "Estratégias para uma narrativa imersiva: Proposta de análise sobre os recursos sonoros de A Blind Legend", apresentada no $41^{\circ}$ Congresso Brasileiro de Ciências da Comunicação. 


\section{Introdução}

Segundo a pesquisa Perspectivas do Cenário Digital: Brasil 2018, realizada pela comScore, o público multiplataforma segue sendo maioria, mesmo com o crescimento do consumo em dispositivos móveis. Mas o mercado mobile tem crescido, tendo hoje o dobro de minutos médios de consumo de mídia em relação ao desktop e um crescimento de $9,1 \%$ no consumo mobile only no mercado brasileiro. Deste tempo, uma média de $80 \%$ é utilizada em aplicativos. Ainda de acordo com a mesma pesquisa, pouco mais de $15 \%$ dos usuários de jogos na Inglaterra o fazem em computadores de mesa, deixando quase 85\% de consumidores de games mobile.

Este cenário, associado à qualificação das conexões à internet em mobilidade e ao barateamento dos dispositivos, é propício ao surgimento de novas possibilidades de entretenimento e imersão através da segunda tela e auxilia a reconfiguração do modo como as pessoas utilizam o tempo. Esse novo comportamento pode ser observado nas salas de esperas, onde antes havia muitas revistas e jornais e hoje as pessoas passam cada vez mais tempo conectadas consumindo produtos tecnológicos, isso inclui redes sociais online, conteúdo musical por streaming e jogos eletrônicos.

As novas possibilidades de consumo de áudio derivadas das tecnologias digitais e das mutações nas práticas culturais e sociais permitem que um novo perfil de audiência experimente novas narrativas (LOPEZ, 2017) inclusive no âmbito sonoro, seja explorando inovações multimídia, como os óculos de realidade aumentada, ou narrativas sonoras imersivas, recurso que acreditamos estar presente no jogo $A$ Blind Legend ${ }^{2}$, objeto de análise deste $\operatorname{artigo}^{3}$.

Os processos de afetações entre a tecnologia e o comportamento dos sujeitos são complexos e não estão vinculados a uma argumentação eminentemente tecnocêntrica, mas alocada em um cenário sociocultural complexificado, que considera as variáveis da nova ecologia de mídia e da entrada no rádio neste espaço (SCOLARI, 2012; CUNHA, 2016). Para Cunha (2016), as mudanças que o meio tem vivido vão além de si próprio, e consideram as práticas sociais contemporâneas como fator de potencialidade do consumo

${ }^{2}$ O jogo A Blind Legend está disponível para o sistema android, IOS e para computadores no Steam. Link do site oficial do game: http://www.ablindlegend.com/en/home-2/ .Acesso: 9 jul. 2018

${ }^{3}$ Pesquisa vinculada ao projeto "Conhecer o ouvinte-internauta: Um estudo sobre o perfil da audiência de rádio no cenário de convergência", financiado pelos editais PROPP Auxílio Financeiro a Pesquisador da UFOP, Chamada CNPq/ MCTI N 25/2015 - Ciências Humanas, Sociais e Sociais Aplicadas, Edital FAPEMIG 01/2015 - Demanda Universal e Edital No 512/2017 - Bolsa de Pesquisador Visitante. 
em dispositivos móveis. A mobilidade (LEMOS, 2013), neste contexto, também é colocada em perspectiva, considerando a relação multidirecional que estabelece com tecnologias, sujeitos e práticas. Ela entrelaça questões tecnológicas, sociais, antropológicas além de afetar diretamente a mobilidade do ciberespaço, como o acesso a máquinas, redes e espaços.

O jogo eletrônico sonoro para dispositivos móveis $A$ Blind Legend é um dos produtos dessa nova ecologia midiática. Sem explorar ícones de interação de referência predominantemente visual tradicionalmente adotados nos aplicativos, como botões, cenários e personagens gráficos, o jogo utiliza apenas o som para criar a experiência no usuário. A imagem se restringe a uma marcação sensorial inscrita nos tons de cinza e preto associados a uma névoa - perenes e estáticas - entremeadas por riscos brancos que demarcam os movimentos realizados pelo jogador. Trata-se então de uma narrativa que gera estranheza e deriva em uma relação de maior intensidade com o usuário, principalmente quando não se trata do público inicialmente pretendido pelos desenvolvedores. Então, pensar um jogo para além de um público específico, os deficientes visuais, e tratar o som como um movimento imersivo e estético, faz com que uma nova experiência seja criada entre os usuários, alterando a relação com os lugares da informação para dar espaço ao sujeito que busca experiências e não territórios específicos, no caso o fato de ser um jogo apenas sonoro.

A demarcação do tempo e do espaço no jogo é fundante da narrativa acústica que se dispõe a, a partir de uma estrutura complexa e diversa, redesenhar um cenário, suas práticas e seus sujeitos. Essa demarcação, que também inclui os movimentos realizados pelos sujeitos e pelo próprio acontecimento central da obra é compreendida neste estudo a partir das paisagens sonoras de Schafer (1977), pensadas como recurso para construção de um mundo ficcional. O papel do compositor como engenheiro de "emoções" apresentada pelo autor está ligado diretamente com a jogabilidade nesta narrativa acústica e é fundamental para que a experiência de imersão seja completa, englobando elementos constitutivos do universo sonoro acionado. Para isso, consideramos também a imersão como um recurso narrativo e não apenas uma estratégia vinculada às tecnologias digitais (LEMOS, 2013; LOPEZ, 2017). Esta opção teórica parte dos argumentos de Domínguez (2015), que defende não a desconsideração do vínculo tecnológico da imersividade, mas a mirada mais ampla, que parte da história, das suas estratégias de composição e não se restringe à tecnologia para o acionamento engajado, envolvente e imersivo da audiência. 
Este potencial imersivo construído a partir da narrativa acústica e que permite ao usuário percorrer os cenários, interagir, agir e determinar os caminhos a seguir é o que mais nos interessa. Então, este artigo se propõe a analisar todas as fases/cenários apresentados pelo jogo A Blind Legend e não apenas para um momento específico. Compreendemos a impossibilidade de esgotar as estratégias sonoras presentes no objeto, mas buscamos, através de um olhar metodologicamente cuidadoso, contemplar uma ampla gama de marcas sonoras e de encadeamentos narrativos para que possamos entender as estratégias acionadas para criar uma atmosfera imersiva.

A DOWiNO ${ }^{4}$, empresa criadora do game lançou em 2015 a primeira aventura de ação móvel que utiliza o som binaural ${ }^{5}$, paga por uma campanha de financiamento coletivo. O cenário é ambientado na Idade Média e o jogador assume os comandos do personagem Edward Blake, um cavaleiro cego que teve sua esposa raptada por um rei malvado que governa o reino com punhos cerrados. Com ajuda de Louise, sua filha de 10 anos, Edward precisa enfrentar batalhas em ambientes perigosos para salvar a sua esposa e reunir a família em segurança.

Para compreender o corpus dessa pesquisa e as suas narrativas, a análise descritiva (TRIVIÑOS, 2008) foi adotada para permitir uma melhor caracterização dos recursos presentes no game sonoro. O dispositivo móvel, seus potenciais de uso e affordances, as estratégias sonoras, as opções do jogo, a entonação dos personagens, a construção de mundo a partir do sonoro e a condução emocional são variáveis que auxiliam na definição de um padrão baseado nas técnicas de análise dedutivas e indutivas.

\footnotetext{
${ }^{4}$ Empresa desenvolvedora do "A Blind Legend”. Disponível em: http://www.dowino.com/en/ .Acesso: 9 jul. 2018

${ }^{5}$ O áudio binaural tem capacidade de iludir o usuário, fazendo o acreditar que está de fato presente nos ambientes (...). Para atingir um nível mais alto de qualidade e ilusão, a técnica busca gravar e reproduzir sons de uma forma que o cérebro é levado a acreditar que o ouvinte está em um mundo virtual. Assim, o som binaural representa para o áudio o mesmo que a realidade virtual promete para as imagens: a sensação 3D de estar em um ambiente complexo e real. Diferente dos métodos de gravação mais conhecidos, o mono (composto por um microfone), e o estéreo (com dois microfones separados para permitir divisão em altofalantes), o som binaural nasce de um processo mais complexo, que reflete na qualidade do som. Esse tipo de gravação é realizado com microfones colocados em uma cabeça de boneco, nos lugares onde estariam os ouvidos. O manequim é feito com materiais que simulam com grande nível de exatidão a consistência e estrutura do crânio humano de modo que o som capturado acaba recriando o campo sonoro original do ambiente em que foi produzido. $\mathrm{O}$ resultado do método são gravações que criam uma sensação de presença, impossível nos processos mono e estéreo. Disponível em: http://www.techtudo.com.br/noticias/ noticia/2016/03/tecnica-de-som-3d-do-seculo-19-cria-mais-imersao-na-realidade-virtual.html .Acesso: 8 jul. 2018
} 


\section{Consumo de áudio em mobilidade}

A ecologia de mídia usa a ecologia como uma metáfora para falar sobre a mídia como ambiente e espécie em permanente evolução. Para entendermos como esse ambiente afeta o contexto social de seus usuários e também é afetado, Cunha (2016) amplia a perspectiva de Scolari (2012) e busca inserir o rádio na "nova ecologia de mídia".

Para a autora, a história do rádio não pode ser definida mais através de períodos de mudança ou de acomodação. "A transformação é cotidiana, interferindo e resultando em choques e mudanças culturais rotineiramente, a partir do próprio uso que a sociedade vai fazendo no processo" (CUNHA, 2016, p. 344). Portanto, devemos considerar este conceito de forma abrangente e que contemple a mídia como ambiente passível de mudanças na vida cotidiana e cultural.

Reconhecendo as contradições do conceito de ecologia da mídia, especialmente as críticas que apontam para um modelo de determinismo tecnológico, Strate (2008) afirma que o entendimento da mídia como um ambiente é o antídoto para o pensamento da mídia em termos de causa e efeito nas relações. Como ambiente, a mídia não determina as ações, mas define possibilidades de ações que possamos ter e facilitam certas ações e desencorajam outras. (CUNHA, 2016, p. 346).

Dessa forma, ao olhar para o rádio e para o áudio, por meio da nova ecologia de mídia, podemos refletir sobre as possibilidades e desdobramentos que essas relações comunicacionais e sociais estabelecem. Falamos aqui de processos evolutivos que geram novas práticas interativas, fluxos de circulação de conteúdo mais dinâmicos e afetados por uma diversidade de sujeitos e um movimento no caminho da descentralização da circulação das informações. Assim, podemos considerar um dinamismo nunca visto, em que essas afetações criam um cenário interligado entre as novas formas de consumo e o próprio ouvinte-internauta, possibilitando inúmeras atividades, que vão além dos dispositivos eletrônicos disponíveis para tal interação. Como lembra Lopez (2016), a audiência do rádio se constitui num cenário complexificado de mudanças não estritamente tecnológicas, mas sociais e culturais que dialogam diretamente com o mercado do rádio e do áudio, com seu conteúdo e com as suas práticas comunicacionais. As tecnologias digitais, então, passam a afetar a própria compreensão do tempo e o protagonismo dos sujeitos nas práticas sociais cotidianas. Da mesma forma, são afetadas por eles, em um 
movimento de retroalimentação das mudanças no diálogo com os meios, nas práticas sociais e comunicacionais e na configuração do que Van Dijk, Poell e De Wall (2018) chamam de sociedade da plataforma, que nos leva a pensar essas mudanças e sua relação com as práticas cotidianas.

[...] descrever a vida na mídia, tomando como base os tipos usados pelas pessoas e como elas desenvolvem atividades através da mídia, é totalmente diferente de definir como todas estas práticas ocorrem ao redor da mídia. Uma vida na mídia é muito mais do que ter uma infinidade de dispositivos eletrônicos à disposição, gastar muito tempo assistindo à televisão ou navegando na web. É executar atividades por intermédio da mídia, é estar envolvido por ela na condição de ambiente (CUNHA, 2016, p.350).

Esse cenário de afetações sociais está ligado à forma como as mudanças no rádio são parte da evolução da sociedade, de seus hábitos, de suas práticas e de seus processos interativos. Se nos primeiros anos do meio ainda massivo o rádio estava atrelado aos grandes aparelhos valvulados - fixos e pesados que ficavam dentro dos ambientes familiares (KOCHHANN et al., 2011), esta realidade mudou - e trouxe consigo dinâmicas de consumo e produção de conteúdo variadas. Com a invenção do transistor, que possibilitou ouvir rádio sem a necessidade de estar conectado a uma tomada, o ouvinte passou a levar o rádio consigo para todos os lugares. Para Ferraretto (2017), nas últimas décadas o uso do telefone celular e da internet foram decisivos para que houvesse uma reconfiguração nas rotinas dos rádios. Esta reconfiguração, como lembra Lopez (2010), não está restrita às tecnologias digitais. O telefone móvel, por exemplo, afetou o rádio musical e sua relação com a audiência que deixava recados em secretárias eletrônicas e o radiojornalismo, já que permitia a realização de entrevistas e dinamismo no contato com fontes e audiência.

A internet, no entanto, aparece como um ponto de mudança fundamental, já que altera produção, consumo e distribuição (LOPEZ, 2010). A apropriação de ferramentas e a presença em plataformas digitais leva a uma potencialização de características essenciais do meio, seguindo o que defende Palacios (2003) ao falar da entrada dos meios tradicionais nestes espaços. Com isso, o diálogo com a audiência se amplia, o imediatismo e o potencial para dar espaço a uma pluralidade de vozes cresce e o caráter local e próximo do rádio assumem protagonismo. A inovação, então, passa a ser pensada a partir não somente do perfil editorial, mas da plataforma e dos interesses diretos do público. 
Hoje, os serviços de streamings possibilitaram uma mobilidade do conteúdo em relação ao indivíduo, reconfigurando de uma forma direta o modelo de distribuição linear. Segundo a pesquisa TIC Domicílios Cultura (CRESCE USO, 2018), essas plataformas são responsáveis pela ampliação do consumo de áudio online. A escuta de música online chega a 59\% dos usuários em conexão móvel 3G ou 4G. Já os jogos eletrônicos, também parte desta nova realidade de consumo de mídia, são consumidos por 75,5\% dos brasileiros, de acordo com a Pesquisa Game Brasil (PESQUISA INDICA, 2018), sendo que $43,6 \%$ dos entrevistados têm preferência pelas plataformas móveis.

Nessa nova realidade, os conteúdos passaram a ser distribuídos por demanda, estabelecendo uma forma de consumo envolvendo a cultura da conexão (JENKINS, GREEN e FORD, 2014), a cultura da portabilidade (KISCHINHEVSKY, 2009) e a cultura do acesso (KISCHINHEVSKY, 2015). O autor explica que a cultura da portabilidade é a "investigação do entorno tecnológico, com ênfase nos usos de aparatos portáteis e na sociabilidade entre seus usuários" (KISCHINHEVSKY, 2009, p. 5), já a cultura do acesso seria "um momento em que os consumidores de mídia sonora tendem a fruir serviços de streaming (pagos ou não), em vez de baixar arquivos digitais da internet e transferi-los para tocadores multimídia ou telefones móveis" (KISCHINHEVSKY, 2015, p.11).

Não se pretende afirmar, evidentemente, que uma cultura (do acesso) substitui a outra (da portabilidade). Seria mais apropriado afirmar que ambas coexistem e se articulam em diversos níveis. A emergência de uma cultura do acesso deve ser relacionada ao estágio atual do processo de digitalização das indústrias midiáticas, que possibilita novas formas de consumo e práticas interacionais sonoras, estimuladas por uma maior praticidade (KISCHINHEVSKY, 2015, p. 11).

Kischinhevsky (2015) chama a atenção para os novos formatos de consumo que a era digital proporciona para as práticas interacionais sonoras. Se antes o rádio era apenas visto como conteúdo para uma sociedade industrial de massa, hoje, na sociedade pósmassiva que conta com mudanças sociais, culturais, tecnológicas e estruturais, o consumo, no âmbito móvel, é caracterizado cada vez mais por uma experiência individualizada. Esta individualização, destacamos, não se iguala ao consumo individual apontado por Kochhann at al (2011), mas se metamoforseou incorporando o compartilhamento característico da cultura da conexão e se constrói predominantemente através do potencial imersivo do produto, de sua estrutura narrativa e de suas dinâmicas de consumo - compartilhado, coletivo ou individual. 


\section{Narrativas sonoras}

As narrativas se configuram em diferentes espaços e utilizam diversos meios, como "a linguagem articulada, oral ou escrita, pela imagem fixa ou móvel, pelo gesto ou pela mistura ordenada de todas essas substancias" (BARTHES, 1972, p.19) para contar histórias. Entre as diferentes definições de narrativas, utilizaremos o conceito adotado por Borges (2017) em sua dissertação sobre universos narrativos em adaptações e narrativas transmídia.

Trabalhamos com o entendimento de que as narrativas tratam de histórias com começo, meio e fim, com sucessão de fatos, em que um acontecimento leva a consequências, e estas desencadeiam outros fatos. Porém, esses acontecimentos não são, necessariamente, contados cronologicamente. Um texto que contenha essa estrutura (sucessão de fatos, contados não necessariamente em ordem cronológica) é uma narrativa (BARTHES, 1972, p.27).

A perspectiva da narrativa estruturada e da sucessão de fatos encadeados não necessariamente em um eixo cronológico é o nosso ponto de partida. Esta organização marcada pelo tempo e conduzida pelas ações dos sujeitos das histórias, numa lógica de indução e consequências é incorporada por A Bling Legend através das estratégias acústicas que conduções as ações do jogador. Como exemplo, podemos citar em um determinado momento do jogo, quando o herói precisa se esconder em um lugar indicado pela filha para que não seja morto pelos inimigos. O jogador tem duas opções, ou toma uma atitude em relação ao personagem no tempo estipulado pelo jogo e a história continua, ou o personagem principal é morto.

A narrativa, então, se conduz não somente pela ordenação dos discursos, mas pelos elementos que permitem acionar o ouvinte, enredando-o no texto e acionando o interesse humano (BORGES, 2017). Ainda que as narrativas, academicamente, sejam mais intensamente estudadas em sua composição textual escrita, podemos observar também em peças sonoras o que Barthes (1972) aponta como modelos hipotéticos de descrição, navegando pelos distintos níveis que compõem a trama narrativa, organizados a partir de suas diferenças para chegar à construção complexa da história. Esta complexificação remete ao próprio enredamento, à própria trama textual, que coordena acontecimentos de modo a organizar temporalidades e articular acontecimentos. Como lembra Borges 
(2017), a condução da narrativa nos caminhos possíveis desta trama - especificamente ao olharmos para o jogo eletrônico como um objeto - se estabelece a partir das alternativas de ação oferecidas ao jogador, que podem ser demarcadas espacial e temporalmente por referentes visuais, de movimento ou acústicos.

Para Henry Jenkins (2004) há características que definem ou não estruturação narrativa, considerando que existem tipos de experiências a serem invocadas neste enredamento, a saber: 1) O autor aponta que nem todos os jogos contam histórias, pois estão mais próximos de uma forma abstrata, expressiva e experimental, como por exemplo, o jogo Tetris que prioriza o raciocínio; 2) A experiência do jogador não pode ser simplesmente reduzida à experiência da história, pois a mecânica do jogo influencia a forma como aquela história será apresentada, contada e "jogada" pelos usuários; 3) A narrativa não precisa ser prescritiva, ou seja, contar tudo o que o jogo faz, pois jogos de sucesso, como o The Sims e Grand Theft Auto abrem o precedente para que os próprios jogadores vivam experiências e descubram por si só as potencialidades narrativas; 4) Todas as mídias possuem a sua forma eficaz de contar histórias, pois as narrativas não são recursos rasos que podem ser transferidas de uma mídia para outra sem que crie uma perda de sentido. Isso quer dizer que o enredamento narrativo pode ser construído através da coordenação de múltiplas plataformas (que podem ser integradas, como nos mostra Borges em sua pesquisa) ou podem ser descoladas, assumindo caminhos narrativos independentes. Além disso, devemos considerar que os games podem apresentar estruturas narrativas complexas ou simplificadas, focadas no raciocínio imediato para solução de problemas pontuais e descolados de uma estrutura temporal e espacialmente organizada junto a um argumento, um enredo da trama textual.

Ao trazer estes pontos, Jenkins (2004) discute a necessidade de romper esse modelo narrativo clássico que enfatiza a exploração de cadeias de eventos causais em prol do espetáculo equilibrado, como a jornada do herói estabelecido por Joseph Campbell; a necessidade de retomar o entendimento de narração, pois muitos roteiros subestimam os jogadores e a sua capacidade de pensar e deduzir informações; e que as narrativas podem ser autônomas independente do formato do game e da mídia.

Lemos (2013) afirma que as interfaces tecnológicas agenciam interatividades homem-tecnologia-mundo, construindo narrativas e ordenando visões. O autor entende que os dispositivos são uma estratégia de organização de dados sobre o mundo, aproximando esta ação com a de contar histórias e ainda discute como os dispositivos, redes, bancos de dados, objetos, lugares seriam os intermediários que agenciariam essa ação. "Podemos 
ver a narrativa como produto da associação em uma rede de atores (LATOUR, 2005), onde sujeitos, lugares, dados e dispositivos são actantes produzindo ação sobre outros no espaço e no tempo" (LEMOS, 2013, p.7).

Partindo da percepção de Schafer (1977) compreende-se então que as narrativas partem para construções de mundos, um contar de histórias que cria um envolvimento com o sujeito e lhe oferece experiências. As narrativas sonoras não são diferentes. Por meio de signos, sinais e símbolos abstratos, o som consegue emular narrativas que vão ao encontro de nossos referenciais. A emulação se constrói a partir da recomposição de cenários, de acontecimentos, de ações e de sensações a partir de elementos acústicos temporalmente organizados. Trata-se de uma coordenação que se apoia em uma memória acústica e/ou em uma identidade sonora de determinado acontecimento ou sequência de ações. "Um evento sonoro é simbólico quando desperta em nós emoções ou pensamentos, além de sensações mecânicas ou funções sinalizadoras, quando possui uma numinosidade ou reverberação que ressoa nos mais profundos recessos da psique" (SCHAFER, 1977, p. 239).

O autor ainda explica que um signo é a representação de uma realidade física que indica o que possa ser algo. $\mathrm{O}$ sinal, diferente do signo, possui um significado específico e estimula uma resposta direta, como por exemplo, o toque do celular. Já os símbolos acústicos possuem uma riqueza maior, pois surgem de forma autóctone em diferentes partes do planeta (SCHAFER, 1977). Esses elementos fazem que a narrativa sonora seja compreendida, não apenas como técnica, mas também como experiência. Eles são responsáveis pela correlação entre os tempos da narrativa, atribuindo a ela uma coerência, uma unidade e também pelo estabelecimento, em uma narrativa exclusivamente ou primordialmente acústica, das relações de causalidade, das conexões entre as linhas da trama textual, dando sentido a cada uma das alternativas de ação oferecidas na narrativa do jogo sonoro.

Esta organização narrativa amplia seu potencial imersivo e de envolvimento do jogador no enredo quando explora a complexidade acústica a partir das noções de perspectiva, distância, intensidade - que compõe a ecologia acústica cotidiana. $\mathrm{O}$ som binaural, que permite essa reconstrução acústica, situa o jogador espacialmente no cenário e auxilia na (re)construção de mundo no universo sonoro. É por meio da paisagem sonora (SCHAFER, 1977) que o mundo toma forma na sonografia. Schafer (1977) afirma que uma paisagem sonora "consiste em eventos ouvidos e em não objetos vistos" (SCHAFER, 1977, p. 24), pois formular uma impressão exata daquilo que está 
sendo ouvido é um exercício mais difícil. Dependendo da forma como a sonografia for apresentada, ou da carga cultural e de vivência do usuário, o mundo sugerido pelo som não será compreendido pelo ouvinte.

$\mathrm{O}$ autor fala da necessidade de compreendemos a ecologia acústica na qual estamos inseridos, dar atenção aos sons do nosso entorno, que marcam a sociedade, e apreciar o mundo como um grande "projeto acústico", considerando a paisagem sonora mundial como uma grande partitura, ou uma composição que se estende à nossa volta. "Somos simultaneamente seu público, seus executantes e seus compositores" (SCHAFER, 1977, p. 287). Para compreender o projeto acústico então, é necessário pensar como compositores desses mundos sonoros. Apesar do som não estar no ambiente material visual, ele suscita visualidades em nosso imaginário, algo que vai além do visual e atravessa os campos de constituição do próprio sujeito. Por isso, o papel do compositor é tão importante para uma narrativa sonora, para viabilizar a coordenação entre os fluxos temporais, a organização dos argumentos e do enredo.

Os compositores são os arquitetos do som. Eles têm a maior experiência em planejar efeitos destinados a provocar respostas específicas nos ouvintes, e os melhores dentre eles são mestres em modular o fluxo desses efeitos para oferecer experiências complexas e variadas, que alguns filósofos têm descrito como uma metáfora para a própria experiência de vida (SCHAFER, 1977, p. 288).

Esse projetista acústico considera, em sua arquitetura da narrativa sonora, as possibilidades de estabelecimento de mundo. Para isso, explora o conhecimento da composição sonora do mundo, observa os referentes e pensa a articulação dos elementos acústicos selecionados para o atendimento de seu objetivo narrativo. No game que analisamos neste artigo as marcas do universo medieval são apresentadas através das armaduras, dos cavalos, das espadas, dos mercados, do ritmo de fala dos sujeitos, a impostação vocal, que aliados ao conteúdo e às transições de ação e de cenário que integram a história permitem que o jogador seja transportado para um tempo distinto do seu tempo de existência.

Ao compreender a relação entre a narrativa, o tecnológico e a construção de mundo a partir do sonoro, consideramos que as narrativas sonoras imersivas são elaboradas com uma perspectiva inovadora, que explora os potenciais da plataforma e do perfil ativo, integrado e conectado das novas audiências (LOPEZ, 2016). Estamos falando então de 
experiências de inovação em rádio, de busca pela apropriação desta ampliação do consumo de conteúdos sonoros, da difusão do consumo de ficção sonora, com a exploração dos potenciais imersivos e o aumento do uso de jogos principalmente pelos usuários mais conectados à internet em dispositivos móveis.

Lopez (2017), tratando especificamente do rádio em plataformas digitais, afirma que as inovações acontecem quando o meio se aproxima do digital em busca da quebra dos padrões na construção de seu conteúdo sonoro ou multimídia, mas sem perder a fala direta com o ouvinte, proporcionado dinâmicas de escuta diferentes, o que potencialmente varia para cada sujeito. Esta mudança nas relações entre o conteúdo e a audiência, assim como o potencial inovador do rádio são afetados diretamente pela aparição de novas tecnologias e seus usos pela audiência. A adoção de aparatos sonoros, como o fone de ouvido e tecnologias de armazenamento e consumo em mobilidade fazem que o som ganhe protagonismo nas novas narrativas.

A adoção de tecnologias e processos inovadores de produção e distribuição de conteúdo depende tanto das tecnologias quanto dos sujeitos. Essas tecnologias nos propiciam dinâmicas de escuta diferenciadas (que variam historicamente, como indicam Kochhann et al em um texto de 2011, mas também a partir das experiências que tensionam as noções de público e privado, como aponta Eric Harvey).

(...) Como consequência, esta e outras tecnologias de armazenamento e difusão alçam o som a um status de protagonista nas narrativas, permitindo consumos imersivos, móveis e inseridos em narrativas complexas (LOPEZ, 2017, p. 9) (tradução nossa).

O jogo A Blind Legend é um exemplo de protagonismo do som na narrativa, apropriado como um artifício para imersão da audiência em um cenário medieval. $\mathrm{O}$ jogo pode ser caracterizado como conteúdo que propicia uma escuta diferente, porém a escuta binaural precisa ser feita através de fones de ouvido, para que a experiência não seja comprometida.

\section{Estratégias narrativas em A Blind Legend}

O game A Blind Legend é praticamente todo sonoro. No material de divulgação, os desenvolvedores reforçam a necessidade de se consumir o jogo por meio de fones de ouvidos para a experiência do áudio binaural seja a mais imersiva possível. Os jogadores precisam confiar inteiramente em sua audição, pois nem o menu do jogo, com opções de 
configuração, possui alguma disposição gráfica visual interativa com botões ou textos. Após iniciar o jogo, um menu sonoro permite começar uma partida nova, continuar uma partida salva, sair do jogo, assinar newsletter, ver os créditos, comprar vidas, mudar configurações, alterar o idioma do game (inglês/francês) e selecionar algum cenário/ fase específica. A única disposição gráfica visual é a névoa que fica evidente a todos os momentos do jogo, o que permite que o jogador se coloque no lugar do protagonista, Edward Blake, em sua aventura medieval.

Figura 1 - Imagem retirada do material de divulgação disponibilizado para o lançamento do jogo.

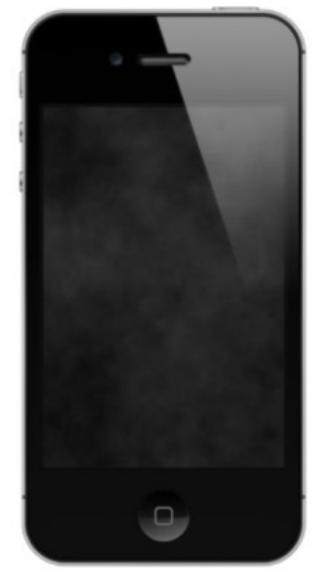

Normal state

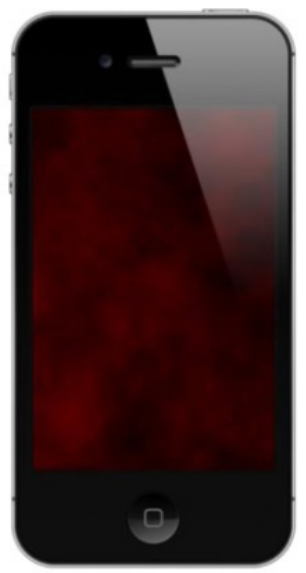

Red Flash and vibration signals that you have been hit!

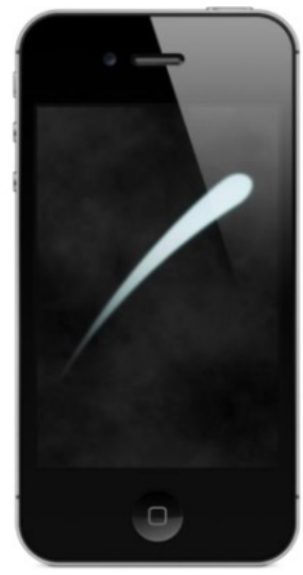

Gestures (here a sword strike)

Fonte: DOWiNO.

Estas são as representações visuais oferecidas pelo jogo. Acompanhado de vibrações do dispositivo sempre que o jogador é golpeado, complementam também a narrativa acústica, composta nas batalhas pela movimentação do jogador, dos demais sujeitos componentes da cena, pelas falas que dão uma perspectiva espacial ao jogador e pelas suas próprias reações do jogo quando erra um ataque, quando é atingido, quando se perde na cena e quando segue o caminho previsto em determinada unidade narrativa.

O personagem principal, Edward Blake, é guiado através do uso da tela do smartphone, ação que só é possível graças à interação com o áudio binaural, que localiza o jogador espacialmente. Os movimentos são controlados através de toques, tornando possível que o personagem ande, corra, ataque com uma espada, se defenda com um escudo ou combine movimentos. 
Figura 2 - Gestos possíveis para condução narrativa

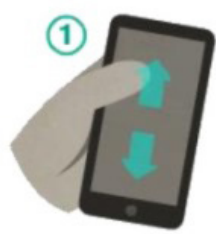

MOVE FORWARL OR BACKWARDS

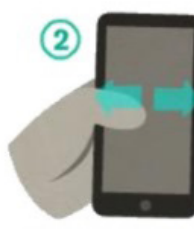

TURN LEFT OR RIGHT

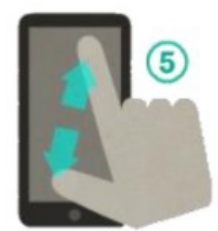

DEFLECT YOUR ENNEMY

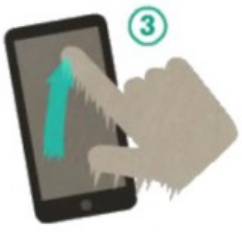

ATTACK OR MAKE COMBINATION MOVES

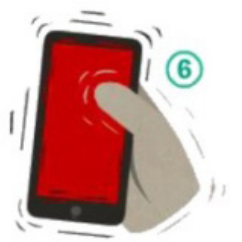

OUCH! TAKING A HIT

Fonte: DOWiNO.

Olhamos para a narrativa do jogo inicialmente a partir de sua estrutura. Em A Blind Legend consideramos, como ponto de partida, que se trata de um jogo prioritariamente acústico, que explora os potenciais da tecnologia digital e a naturalidade das ações inscritas nas affordances dos dispositivos móveis, como os movimentos de pinçar, tocar e arrastar. Assim, os movimentos necessários, desenvolvidos em um cenário visual inexistente, não retiram o jogador de seu processo imersivo.

A parte técnica e de comandos, à primeira vista, pode parecer complexa. Porém ao iniciar o jogo, uma voz introduz a história e ensina os comandos e ações através dos gestos. Em todos os momentos em que ela enuncia algo, fica claro para o jogador que se trata de alguma informação técnica, relacionada aos comandos, deslocando o ouvinte do mundo sonoro medieval para um estado de aprendizado. A sua entonação é sempre constante, como uma fala imperativa que se desloca do padrão acústico do universo.

Após esse momento inicial da exposição da jogabilidade, o jogador é apresentado ao "sentido direcional" do personagem principal. Louise Blake, a filha do herói, serve como uma bússola para o jogador. Através de uma fala imperativa, mas tom próximo, como this way e over here, e condução emocional em situações de perigo eminente, Louise determina o estado de alerta em que o usuário precisa estar. O roteiro do jogo aponta Edward como o personagem principal, porém, ao analisar a narrativa sonora, podemos 
inferir que a filha é a guia e pode ser caracterizada como co-protagonista, pois sem as suas exposições de ordem e orientação, o herói não avançaria. Louise usa um recurso de localização espacial dentro de um ambiente criado pelo sonoro. Apesar de compor a narrativa, a sua principal função é apontar direções e não construir mundos a partir do som (SCHAFER, 1977). Ela é um recurso essencial para a narrativa sonora, seja por meio de sua entonação, caso o seu pai esteja longe do objetivo, ou pela sua orientação espacial.

A construção de mundo a partir do sonoro neste jogo aciona três perspectivas: a paisagem sonora, a percepção de volume dos sinais e a imersão sonora. A paisagem sonora, identidade constituída por meio do som, que está presente em todos os lugares como um grande projeto acústico, aparece em todas as fases. O jogador consegue perceber em qual cenário está inserido, seja um vilarejo, floresta ou batalha. Ao construir o cenário do vilarejo, por exemplo, o compositor sonoro precisa suscitar imagens mentais no ouvinte através da paisagem sonora, para que ele "veja" o mundo a sua volta. São usados sons de galinhas, cavalos galopando, carroças, crianças brincando, civis andando em terra batida e ferreiro e carpinteiro trabalhando. A constituição de mundo acústico evidencia a preocupação do compositor em estabelecer um mundo crível, um cenário de densas caracterizações e um forte projeto acústico, o que intensifica o potencial imersivo da narrativa e auxilia na tomada de decisões do jogador em relação às suas alternativas de ação.

Estabelecido o projeto acústico, a identidade de mundo, o jogo utiliza o volume para invocar a sensação de espacialidade, e com isso ampliar a imersão. Quanto mais próximo de uma identidade sonora, o sinal (som que remete a uma ação e reação direta) fica em evidência, mais alto. A percepção de localização do objeto que origina o som também se destaca nesta variável e permite uma organização das ações do jogador, que pode se esconder, atacar, fugir ou, nas batalhas, se defender.

A mesma lógica se aplica para os casos em que o personagem se afasta daquele sinal. Por exemplo, em um determinado momento, o herói precisa pegar a sua espada que está sendo consertada pelo ferreiro. Ao iniciar este cenário, o jogador percebe acusticamente o ferro sendo batido por um martelo. Após um diálogo sobre onde está a espada no cenário, o jogador anda pelo vilarejo e percebe a aproximação ou afastamento do objeto na cena a partir da composição espacial, da perspectiva e do volume deste sinal na ambiência sonora. O propósito é alcançado quando os sons do metal e do ferreiro se tornam predominantes. Essa variação de localização entre os sinais, suscita uma espacialidade e uma imersão que são potencializadas pela orientação de Louise e pela técnica do áudio binaural. 
O jogo apresenta uma dinâmica demarcada pela imersividade narrativa coordenada com as ações necessárias junto à tela do dispositivo móvel. A variação de intensidades na interação em momentos de movimentação pelo cenário, mais leves, e de batalhas, mais intensas, demandam igualmente a atenção por serem conduzidas acusticamente. $A$ Blind Legend, então, exige do jogador uma atenção concentrada na composição acústica para que possa percorrer os tempos narrativos e compreender o desenho do cenário e o desenrolar dos acontecimentos. Esta atenção potencializa o entrelaçamento dos pontos narrativos da trama textual, atribuindo maior protagonismo às ações do jogador e ampliando a aproximação entre sujeitos e narrativa.

\section{Considerações Finais}

A evolução tecnológica em relação aos dispositivos móveis tem potencializado um novo formato de distribuição e consumo de conteúdos em mobilidade, interferindo em costumes rotineiros, alterando o ambiente e definindo novas possibilidades de ações (CUNHA, 2016). Ao mesmo tempo, a cultura do acesso (KISCHINHEVSKY, 2015); possibilita novas práticas de consumo em áudio que adequadas ao perfil das novas audiências permitem explorar narrativas inovadoras que ampliam o potencial imersivo do consumo de produtos acústicos.

As interfaces tecnológicas agenciam construções de narrativas (LEMOS, 2013), entre o humano, máquina e mundo, algo que o objeto deste artigo utiliza a partir da interação direta pela tela touch do dispositivo móvel e relacional pela necessidade de consumo por fones de ouvidos, resultando em uma narrativa que utiliza a mecânica do jogo como aliada para estabelecer uma evolução dos eventos narrados sem quem a experiência do jogador seja reduzida pela história (JENKINS, 2004). Além disso, os usos desses recursos fazem que o som ganhe protagonismo nessas novas narrativas (LOPEZ, 2017) permitindo consumos imersivos e móveis.

A análise nos leva a entender como a narrativa imersiva é criada por meio do sonoro, utilizando estratégias que fundem ordens imperativas, entonação, a paisagem sonora como identidade de mundo (SCHAFER,1977), sinais como resposta direta e o áudio binaural como técnica imersiva, para inserir o jogador em um cenário acústico de múltiplas afetações sonoras.

Essas estratégias podem variar de cenário, ou até mesmo para o produto, mas revelam a importância de pensar narrativas imersivas sonoras que estejam vinculadas 
à sociedade da plataforma (considerando os usos dados a elas e as suas implicações nas práticas sociais, comunicacionais e de consumo) que possibilitem apropriações da mobilidade, das affordances dos dispositivos móveis, que explorem o som como construção de mundo, como o trabalho fundamental do compositor sonoro, e a experiência imersiva.

Olhar para o fenômeno dos games sonoros deslocando-o do campo das audiências específicas e pensando seu papel na construção de cenários e no adensamento narrativo das práticas de entretenimento da sociedade contemporânea apresenta-se como um desafio - ainda não plenamente atendido. Neste artigo, uma aproximação a um objeto complexo, buscamos apontar potencialidades da narrativa acústica no caminho da imersividade, do engajamento e do acionamento de audiências. O estudo descritivo que desenvolvemos revelou um número maior de camadas nessa teia narrativa do que imaginávamos localizar inicialmente e demonstrou que as variáveis a serem observadas em uma pesquisa sobre games sonoros devem ir além do próprio som, mas considerar as dinâmicas de circulação e consumo, a ecologia dos jogos, o potencial de jogabilidade, os sujeitos acionados, as affordances exploradas e a narrativa em si.

Observamos, como consequência deste estudo, que a aproximação aos estudos da narrativa radiofônica, da estética acústica e das paisagens sonoras permite compreender meandros da trama alinhados - de forma intencional ou não - e que ampliam ou minimizam o papel do jogador na condução da narrativa. A sonoridade, elemento central do estudo e do objeto, revela desafios tanto a esse jogador quanto ao pesquisador que busca compreender percursos, escolhas e desafios do game sonoro.

\section{Referências}

BARTHES, Roland et al. Análise estrutural da narrativa. Tradução de Maria Zélia Barbosa Pinto. Petrópolis (RJ): Editora Vozes, 1972.

BORGES, Aline Monteiro Xavier Homssi . Personagens e universos narrativos em adaptações e narrativas transmídia: análise de A dança dos dragões e produtos derivados. Dissertação (Mestrado em Comunicação). Universidade Federal de Ouro Preto. Ouro Preto, 2017. Disponível em: http://repositorio.ufop.br/handle/123456789/8021 
CUNHA, Magda. O Rádio na nova tecnologia de mídia. In: ZUCULOTO, Valci; LOPEZ, Debora Cristina; KISCHINHEVSKY, Marcelo (orgs.). Estudos Radiofônicos no Brasil: 25 anos do Grupo de Pesquisa de Rádio e Mídia Sonora da Intercom. São Paulo: INTERCOM, 2016.

CRESCE USO da internet para consumo de áudio e vídeo. Revista Encontro. Disponível em: https://www.revistaencontro.com.br/canal/brasil/2018/11/cresce-uso-da-internet-para-consumode-audio-e-video.html, acesso em: 23 nov. 2018.

DOMÍNGUEZ, Eva. Periodismo inmersivo o cómo la realidad virtual y el videojuego influyen en la interfaz e interactividad del relato de actualidad. El profesional de la información, v. 24, n. 4, pp. 413-423, 2015.

JENKINS, Henry. Game Design Narrative Architecture. 2004. Disponível em: http://www. electronicbookreview.com/thread/firstperson/lazzi-fair. Acesso em: 24 jul. 2016

JENKINS, Henry, GREEN, Joshua, FORD, Sam. Cultura da conexão. Criando valor e significado por meio da mídia propagável. São Paulo: Aleph, 2014.

KISCHINHEVSKY, Marcelo. Cultura da portabilidade - Novos usos do rádio e sociabilidades em mídia sonora, Lisboa: Observatorio (OBS*), v. 3. 2009

KISCHINHEVSKY, Marcelo. Cultura da portabilidade à cultura do acesso - a reordenação do mercado de mídia sonora. In: CONGRESSO INTERNACIONAL IBERCOM. 14., 2015. Anais [...]. São Paulo, Universidade de São Paulo, 2015.

KISCHINHEVSKY, Marcelo. Rádio e mídias sociais: mediações e interações radiofônicas em plataformas digitais. Rio de Janeiro: Mauad X, 2016.

KOCHHANN, Roscéli; FREIRE, Marcelo; LOPEZ, Debora Cristina. Rádio: convergência tecnológica e a evolução dos dispositivos. In: ENCONTRO NACIONAL DE HISTÓRIA DA MÍDIA, 8., 2011, Guarapuava. Anais [...]. São Paulo: Rede Alcar, 2011. v. 01.

LEMOS, André. Realidad aumentada. Narrativa y médios de georreferencia. Versão em português do artigo. In Sánchez, Amaranta (org). Móbile. Reflexión y experimentatión en torno a los médios locativos em el arte contemporâneo en México., Consejo Nacional para La Cultura y lãs Artes / Centro Multimedia - CENART, México, DF, 2013. 
LOPEZ, Debora Cristina. La radio en narratives immersives : le contenu journalistique et l'audience. in Sebastien Poulain (sous la direction de), « La radio du futur : du téléchromophotophonotétroscope aux postradiomorphoses », Cahiers d'histoire de la radiodiffusion, $\mathrm{n}^{\circ} 132$, avril - juin, 2017.

LOPEZ, Debora Cristina. (Re)Construindo o conceito de audiência no rádio em cenário de convergência. In: ZUCULOTO, Valci; LOPEZ, Debora Cristina; KISCHINHEVSKY, Marcelo (orgs.). Estudos Radiofônicos no Brasil: 25 anos do Grupo de Pesquisa de Rádio e Mídia Sonora da Intercom. São Paulo: INTERCOM, 2016.

LOPEZ, Debora Cristina. Radiojornalismo Hipermidiático: tendências e perspectivas do jornalismo de rádio all news brasileiro em um contexto de convergência tecnológica. Covilhã: Labcom Books, 2010. Disponível em: http://www.labcom-ifp.ubi.pt/ficheiros/20110415-debora lopez_radiojornalismo.pdf. Acesso em:

PALACIOS, Marcos. Ruptura, continuidade e potencialização no jornalismo on-line: o lugar da memória. In: MACHADO, Elias; PALACIOS, Marcos (Eds.). Modelos de jornalismo digital. Salvador: Calandra, 2003.

PERSPECTIVAS do Cenário Digital: Brasil 2018. comScore. Disponível em: https://goo.gl/ mr8EnA. Acesso em: 19 nov. 2018.

PESQUISA INDICA que 75,5\% dos brasileiros consomem jogos eletrônicos. Pesquisa Game Brasil. Disponível em: https://www.pesquisagamebrasil.com.br/ign-pesquisa-indica-que-755dos-brasileiros-consomem-jogos-eletronicos/. Acesso em: 23 nov. 2018.

SCOLARI, Carlos A., Media Evolution: Emergence, Dominance, Survival, and Extinction in the Media Ecology - Licensed under the Creative Commons Attribution Non-commercial No Derivatives (by-nc-nd). Disponível em: http://ijoc.org. Acesso em:

SCHAFER, R. Muray. A afinação do mundo: uma exploração pioneira pela história passada e pelo atual estado do mais negligenciado aspecto do nosso ambiente: a paisagem sonora. Tradução Marisa Trench Fonterrada. São Paulo: UNESP, 2001.

TRIVINOS, Augusto Nibaldo Silva. Introdução à pesquisa em ciências sociais: a pesquisa qualitativa em educação. São Paulo: Atlas, 1987. 
VAN DIJCK, José; POELL, Thomas; DE WAAL, Martíjn. The Platform Society: Public Values in a Connective world. New York: Oxford University Press, 2018.

1 Debora Cristina Lopez é doutora em Comunicação pela Universidade Federal da Bahia e professora do Programa de Pós-Graduação em Comunicação e da graduação em Jornalismo da Universidade Federal de Ouro Preto. Coordena o Grupo de Pesquisa Convergência e Jornalismo (ConJor) e o Laboratório de Inovação em Jornalismo (Labin), ambos na UFOP. E-mail: debora.lopez@ufop.edu.br

2 João Alves é mestrando em Comunicação pela Universidade Federal de Ouro Preto. É membro do Grupo de Pesquisa Convergência e Jornalismo (ConJor) e do Laboratório de Inovação em Jornalismo (Labin), na mesma instituição. E-mail: joao. almeidaalves@gmail.com 